\title{
Concepções de lideranças de saúde sobre saúde bucal e controle de políticas públicas
}

\author{
Marco Antonio Manfredini*; Paulo Capel Narvai**
}

* Pesquisador do Centro Colaborador do Ministério da Saúde em Vigilância da Saúde Bucal (CECOL) da Faculdade de Saúde Pública da Universidade de São Paulo

** Professor Titular Faculdade de Saúde Pública da Universidade de São Paulo

Recebido em 22/05/2017. Aprovado em 26/11/2017.

\begin{abstract}
RESUMO
Analisam-se as representações sociais sobre saúde bucal e controle social entre lideranças na Área da Saúde em São Paulo. A pesquisa foi qualitativa, com orientação analítico-descritiva, utilizando o procedimento metodológico do Discurso do Sujeito Coletivo. O processo saúde-doença foi reconhecido como socialmente determinado. A não identificação da saúde bucal como prioridade foi atribuída à falta de preocupação da população, aos fatores econômicos e aos governos. As lideranças apontam que a assistência odontológica pública é insuficiente para garantir o acesso; não é resolutiva; tem problemas de infraestrutura; e dispõe de profissionais que não atendem às exigências da comunidade.
\end{abstract}

Descritores: Políticas Públicas de Saúde. Acesso aos Serviços de Saúde. Participação Comunitária. Serviços de Saúde Bucal.

\section{INTRODUÇÃO}

A saúde bucal é parte integrante e indissociável do conceito de saúde. As atividades de saúde bucal desenvolvidas nos serviços públicos devem contemplar ações de promoção, prevenção, cura e reabilitação. $\mathrm{O}$ acesso à assistência odontológica é um dos principais problemas de saúde pública no Brasil. Aspecto pouco abordado sobre o assunto, diz respeito às ações dos movimentos organizados da população para garantir este direito. A participação da comunidade é uma das diretrizes do Sistema Único de Saúde (SUS). A Lei Federal $n^{\circ}$ 8.142/90, ao dispor sobre a participação da comunidade na gestão do sistema, aponta a Conferência de Saúde e o Conselho de Saúde como instâncias colegiadas do SUS, em cada esfera de governo ${ }^{1}$.

Odontologia e saúde bucal foram objetos de preocupação desde a $1^{\mathrm{a}}$ Conferência Nacional 
de Saúde (CNS), em 1941. Nos registros desta CNS há perguntas sobre a assistência odontológica aos escolares nos questionários sobre a situação educacional e cultural dos estados, a situação sanitária, fiscalização e exercício profissional. Até a $9^{\mathrm{a}} \mathrm{CNS}$ eram esparsos os relatos sobre Odontologia e saúde bucal, com a notável exceção da $7^{\mathrm{a}} \mathrm{CNS}$. A partir da $10^{a}$ CNS (1996), as proposições ficaram mais consistentes traduzindo-se em propostas de reorganização dessas ações no âmbito do $\mathrm{SUS}^{2,3}$.

A organização dos movimentos populares de saúde no município de São Paulo remonta aos meados da década de 1970, na zona Leste. Na região do Jardim Nordeste, foi constituída a primeira Comissão de Saúde, que foi responsável pela organização do movimento de saúde na região e pela disseminação desse tipo de discussão da questão da cidadania e saúde em outros grupos comunitários da cidade ${ }^{4}$. Na mesma década, em outras regiões do município, também se estruturam movimentos populares de saúde. Estes movimentos diferiam em razão das condições que decorreram de suas evoluções históricas, com uma organização precária e dependente do sucesso de suas lutas, do apoio externo obtido e das relações mantidas na esfera institucional, com governos e partidos políticos

Em junho de 1997, realizou-se o I Encontro dos Movimentos Populares de Saúde da cidade de São Paulo, quando foi criada a União de Movimentos Populares de Saúde (UMPS). Os documentos e resoluções dos encontros da UMPS demonstravam que, nestes eventos, os movimentos procuravam dar destaque à participação da Central de Movimentos Populares e de outros parceiros, como a Igreja Católica, centros de formação e elaboração de políticas, instituições universitárias e parlamentares nas lutas sociais. A existência da
UMPS permitiu pautar temas que não estavam no centro das atenções dos movimentos de saúde, como o planejamento da cidade; orçamento participativo; desemprego; violência e políticas públicas intersetoriais ${ }^{5}$.

Analisando-se a documentação produzida pela UMPS nesse período, identificou-se que a temática de saúde bucal não aparecia com destaque, ao contrário de outras áreas como saúde da família, da mulher, da criança, do adolescente, do adulto e vigilância sanitária. Desta forma, o presente artigo se propõe a analisar se os cuidados em saúde bucal são sentidos como necessidade por lideranças da UMPS e como estas lidam com o tema da saúde bucal.

\section{METODOLOGIA}

Trata-se de pesquisa qualitativa, com orientação analítico-descritiva, mediante realização de grupos focais com lideranças da UMPS. Para a análise dos dados, foi utilizado o procedimento metodológico do Discurso do Sujeito Coletivo (DSC). Maior cidade brasileira, São Paulo constitui-se num local de referência e de influência sobre o restante do país, pela diversidade social, étnica, histórica, cultural, política e ideológica que a constitui. Muito embora os resultados deste estudo não possam ser extrapolados para o restante do país, são indicativos das reflexões sobre o assunto no cenário brasileiro, face à importância e características ímpares desta cidade.

A UMPS realiza encontros gerais anuais e reuniões ordinárias mensais. Para abordar o grupo, foram realizadas duas participações nas reuniões ordinárias mensais da UMPS. Na oportunidade, foram apresentados os objetivos e solicitada a participação de interessados na pesquisa. Trinta e um integrantes da UMPS 
compareceram às sessões do grupo focal, realizadas em três finais de semana, aos sábados pela manhã, na Faculdade de Saúde Pública (FSP) da Universidade de São Paulo (USP). Os trinta e um participantes foram divididos pelas três sessões. Inicialmente, cogitou-se a realização de 4 a 5 sessões de grupos focais. Ao final da terceira sessão, constatou-se a saturação das representações nos depoimentos coletados, o que resultou no término das sessões. Essas se esgotaram em virtude da previsibilidade de resposta. A estrutura de significados teria sido apreendida, pois os grupos não apresentavam novidades em termos de conteúdo e argumentos, que se tornavam repetitivos.

As entrevistas em grupo foram realizadas com prévia concordância dos entrevistados, os quais foram esclarecidos quanto aos objetivos da pesquisa e assinaram o Termo de Consentimento Livre e Esclarecido, nos termos da Resolução CNS 196/96. A pesquisa foi aprovada pelo Comitê de Ética em Pesquisa (COEP) da FSP/USP. Cada reunião de grupo focal durou aproximadamente 90 minutos, em território neutro e de fácil acesso aos participantes, respeitando o número preconizado na literatura (6 a 15 componentes por grupo $)^{6}$, sendo conduzida por duas moderadoras, psicólogas especializadas em dinâmica de grupo. O pesquisador não participou dos grupos focais e os encontros foram gravados e transcritos por profissional especializado.

As perguntas foram conduzidas a partir da abordagem mais geral para a mais específica. Foram realizadas perguntas abertas, pois estas permitem que os indivíduos entrevistados se expressem livremente, produzindo discursos. $\mathrm{O}$ roteiro de questões orientou o trabalho nos grupos focais, com variações no tempo dedicado a cada uma, nas três sessões.
Para a organização e apresentação dos dados, foi utilizado o procedimento metodológico do DSC, recurso metodológico destinado a tornar as representações sociais mais claras e expressivas, permitindo que um determinado grupo social possa ser visto como autor e emissor de discursos comuns. Com o sujeito coletivo, os discursos não se anulam nem são reduzidos a uma categoria comum unificadora. A utilização dessa técnica de análise busca reconstruir tantos discursos-síntese quantos se julgue necessários à expressão de um dado pensamento ou representação social sobre um fenômeno. Tendo como fundamento a teoria da Representação Social e seus pressupostos sociológicos, o DSC consiste basicamente em analisar o material coletado, extraído de cada um dos depoimentos ${ }^{6}$.

\section{RESULTADOS E DISCUSSÃO \\ Caracterização dos participantes}

Dos entrevistados, 17 (54,8\%) eram mulheres e 14 (45,2\%) homens. Em relação aos graus de escolaridade, $2(6,5 \%)$ tinham $1^{\circ}$ grau incompleto, $3(9,7 \%) \quad 1^{\circ}$ grau completo; 17 $(54,8 \%) 2^{\circ}$ grau completo; e $9(29,0 \%)$ nível superior. Em relação à idade, estas variaram de 43 a 72 anos de idade, sendo que 4 (12,9\%) tinham entre 41 e 50 anos; 14 (45,2\%) entre 51 e 60 anos; 10 (32,2\%) entre 61 e 70 anos; e 3 $(9,7 \%)$ entre 71 e 80 anos. Em relação ao tempo de inserção no movimento popular de saúde, 13 $(41,9 \%)$ tinham até 10 anos; $5(16,1 \%)$ entre 11 e 20 anos; 7 (22,6\%) entre 21 e 30 anos; 3 (9,7\%) mais de 30 anos; e $3(9,7 \%)$ não informaram.

\section{$1^{\text {a }}$ temática: Saúde bucal é prioridade? Como é isto para você?}

Para esta questão, os seguintes DSC foram categorizados: 
Ideia Central A: Sim, pela relação com a saúde geral

"A saúde começa pela boca. A nossa boca é um cartão de visita. A gente fala de saúde bucal que é tudo, que é por onde você mastiga, que é por onde você ingere a sua alimentação. O bucal está ali fisicamente ligado com problemas gástricos, com problemas no esôfago, enfim, uma série de outras coisas, problemas inclusive mandibulares, dores de cabeça, dor de ouvido, é muito mais profundo do que se pode imaginar. E hoje você vê por exemplo, tratados psicológicos, tratados psiquiátricos, de pessoas que têm problemas de não sorrir, de crianças com problemas porque elas têm que colocar aparelho, não por estética, mas porque elas realmente estão deformadas, têm pessoas que ficam deformadas. Então aí você começa a perceber e fala: opa, espera um pouco, dente não é mais estética! Dente é uma necessidade!"

Ideia Central B: Não, pela população.

"A saúde bucal, infelizmente não é prioridade, não para nós. Nós, usuários, população de uma maneira geral. Não está introjetado para a gente que a saúde bucal, ela deve fazer parte, pelo menos é o que a gente conversa em todos os lugares, que ela deve fazer parte da saúde como um todo. Isso é um problema de saúde, mas na nossa consciência não é, nós não vemos isso como doença, a sociedade não vê como doença, não encara como doença. Se doer aí que vira um problema de saúde. A gente nunca votou a bucal como sendo uma parte importante, e o bucal estava muito ligado, principalmente a estética."

Ideia Central C: Não, por fatores econômicos

"Mas dá para ser prioridade a saúde bucal, com um preço que é você tratar um dente? Como um assalariado vai pagar um dente? Não tem condições. Então eu olho para a televisão e eu vejo aquela coisa inatingível, você vai no dentista, como é que eu posso fazer um tratamento de um dente, dois dentes $e$ vou pagar cinco mil reais."

Ideia Central D: Não, pelos governos

"A saúde bucal não é prioridade para governo nenhum."

Ideia Central E: Não, pela relação com a saúde geral

"A odontologia não é uma das prioridades porque nunca ouvi que alguém morresse por causa de um dente."

Os estudos sobre representação social de saúde bucal no Brasil foram realizados com populações urbanas e rurais, em sua maioria usuárias de serviços públicos de saúde ${ }^{7}$. O entendimento de que sujeitos sociais concebem diferentes sentidos à sua boca é constatação importante para a odontologia e a apreensão dos sentidos e significados daquela em diferentes realidades sociais ${ }^{8}$.A inexistência de estudos com a percepção de lideranças de movimentos populares de saúde no país deve ser realçada, face à importância do debate sobre "controle social" e da "saúde bucal coletiva" no país, nos últimos anos.

As representações sociais de saúde bucal das lideranças de movimentos populares de saúde em São Paulo expressam os sistemas de valores, noções, práticas, aspirações, 
significados, desejos e interesses, com que vêem o mundo e as relações em sociedade. Ao se analisar o discurso de lideranças da UMPS, observa-se que houve dois entendimentos antagônicos em relação à saúde bucal: entendida como prioritária e não-prioritária. A constituição da saúde bucal, como necessidade, expressa uma produção social, relacionada às condições sociais de vida das pessoas, tradições históricas, hábito social e representações sobre o corpo e o processo saúde-doença. A necessidade ou carência sentida da atenção odontológica não encontra justificativa somente nas dores e privações que são submetidos os indivíduos das camadas populares ${ }^{9}$.

Para as lideranças da UMPS que defendem a saúde bucal como prioridade, esta, na maior parte dos discursos, baseia-se na associação à saúde geral. Esta associação da saúde bucal à saúde geral foi constatada em estudos anteriores, em que a importância dos dentes e a necessidade de tratamentos foi ressaltada, devido a correlações entre as complicações orgânicas que poderiam advir da falta de saúde bucal ${ }^{10}$; pela preservação da função mastigatória relacionada com a presença de dentes ${ }^{11}$ e pelo desempenho de funções biológicas, como mastigação e digestão, e psicossociais, como a linguagem, o afeto e a auto-estima $^{8}$. A saúde foi associada às condições de vida, superando o modelo biomédico do processo saúde-doença.

O não reconhecimento da saúde bucal como prioridade foi atribuído à população, aos fatores econômicos, aos governos e à falta de vinculação entre saúde bucal e saúde geral. Ressalte-se que a culpabilização da população pela não-priorização da saúde bucal apareceu em vários relatos. Esta é coerente com uma visão de responsabilização do indivíduo pela doença e pela busca do tratamento apenas em momentos de dor. Este achado foi constatado em estudos em que o adoecimento bucal foi associado às normas odontológicas de higiene e dieta ${ }^{7}$; em que a perda de dentes foi contextualizada como de responsabilidade individual, pela falta de trato, facilidade e cuidado ${ }^{12}$.

A não especificação da doença oral foi identificada em estudo que constatou que a boca e seus problemas de saúde estariam implícitos na saúde geral, uma vez que a especificidade e a fragmentação seriam características do saber científico hegemônico. A sensação de estar doente, em relação à "saúde oral", só seria compreendida na perspectiva da manutenção e da reprodução da força de trabalho ${ }^{13}$.

A importância do fator econômico como limitador do acesso à saúde bucal foi constatada em outros estudos. As camadas populares não têm acesso a tratamento odontológico, mesmo com enormes necessidades, devido a seu preço elevado $^{14}$; a imagem do cirurgião-dentista é vinculada a um alto custo de tratamento, principalmente entre indivíduos com mais de 50 anos ${ }^{15}$; é fator que impossibilita tratamentos mais adequados, contribuindo para a perda precoce de dentes ${ }^{16}$; induz à realização da exodontia, por ser uma alternativa mais simples, barata e rápida, na busca da eliminação imediata da dor ${ }^{\mathrm{r} 10}$; impede a realização de tratamentos odontológicos em escolares, gerando sentimento negativo nas mães destes ${ }^{7}$.

Dois exemplos ilustram as demandas por tratamento dentário, por parte de setores populares no município de São Paulo. Muito embora estes dados não possam ser extrapolados para o conjunto do país, são sugestivos de reflexão, face à diversidade constitutiva dessa cidade. No processo de elaboração do Orçamento Participativo (OP) da Prefeitura Municipal de São Paulo para o ano de 2002, constata-se que a 
saúde bucal foi a segunda especialidade mais exigida pelo público que participou das plenárias, só sendo superada pelo Programa Saúde da Família (PSF).

Pesquisa realizada pela UMPS em 2002 e 2003, sobre atendimentos conseguidos e não conseguidos ( $\mathrm{n}=1.921)$ em 221 Unidades Básicas de Saúde (UBS) do município, constatou como principal problema para os usuários, o acesso ao "tratamento de dentes": 50,5\% dos entrevistados relataram não ter conseguido acesso a serviços de assistência odontológica nas UBS da capital. Para se ter uma idéia da dificuldade do acesso à assistência odontológica, em relação às outras demandas, $56,5 \%$ dos entrevistados se consultaram com psicólogos, $82 \%$ tiveram acesso a vacinas e $88 \%$ receberam controle de pressão.

$2^{\text {a }}$ Temática: Você pode me explicar como vê a universalização na saúde bucal?

Ideia Central A: A assistência odontológica é para crianças

"Quando a gente era criança, a gente tinha dentista na escola, e bons. Inicialmente na saúde pública, existiam os dentistas só nas escolas, então só cuidava das crianças."

Ideia Central B: A assistência odontológica é universal

"Eu estranhei agora na ultima vacina, vacinação para idoso, eu fui levar o meu pai, e minha tia e eles exigiram que fizessem uma análise bucal, e eu achei assim um avanço, nunca tinha visto isso. O que temos para oferecer para a saúde bucal do idoso, da criança, do adolescente, porque hoje o idoso está todo banguelo aí porque não tem aonde você se tratar. $O$ adulto precisava ser atendido também, aí começou aquelas histórias de quem não tinha dentes, a questão das idades, dos desdentados."

O princípio da universalização na saúde bucal gerou discursos contraditórios entre as lideranças. Estas detinham suficiente conhecimento sobre o tema da universalidade em saúde. Houve uma forte presença da ideia de que a assistência odontológica deve ser dirigida para as crianças, com a presença de cirurgiões-dentistas nas escolas. Parte desta provém de experiências vivenciadas pelos entrevistados. Ao associar à falta de prevenção à ausência de profissionais nas escolas, destaca-se a dissociação entre o saber técnico e o saber popular, pois desde meados da década dos 1980, preconiza-se que a escola não seja o locus da assistência odontológica.

\section{$3^{\text {a }}$ Temática: Fale sobre a assistência prestada na rede pública municipal}

Ideia Central A: A assistência odontológica não dá acesso

"Não estamos falando que o serviço que é prestado é ruim, nós estamos falando que o serviço que tem é insuficiente. Tiraram os dentistas das escolas e trouxeram para a atenção básica, só que não formaram uma rede de atendimento, de atenção. $O$ governo fala, quando tem trezentos lá na fila de espera, não! Não vai fazer inscrição mais! Não consigo entender é essa tal de saúde bucal, que tem três dentistas dentro da Unidade de Saúde e o ano inteiro você está lá e tem uma fila, tem uma fila, você não sabe quanto saiu e nem quanto entrou. Você para conseguir consulta com o dentista para fazer uma simples obturação, você espera três, quatro, cinco meses."

Ideia Central B: A assistência odontológica pública não é resolutiva. 
"Eu tenho que fazer o tratamento dentário, mas é um serviço que eu não vou achar, até porque muitos dos tratamentos o serviço público não oferece. A pessoa precisa do atendimento e você vai aqui, fica que nem bolinha, que nem ioiô, vai aqui, vai ali, vai acolá, e nada se resolve. Quando você marca uma consulta para o dentista para daqui quarenta e cinco dias, o pessoal já desistiu porque já saiu do padrão... você está conseguindo me entender?... saiu do padrão de rapidez de São Paulo; Aí se você tiver que fazer a restauração de um dente, eles não fazem, aí você perde o dente, e você vai precisar de um implante, que é mais caro ainda."

Ideia Central C: A assistência odontológica pública é ruim, devido à falta de manutenção e condições organizacionais

"São equipamentos delicados, esses aparelhos, e dificilmente esses negócios estão funcionando, sempre, olha tem o dentista, mas queimou o aparelho, quebrou uma pecinha lá, às vezes é um negocinho que tinha lá para raspar. Estamos com os equipamentos, nós temos quatro cadeiras, três estão quebradas, uma para funcionar na semana passada, os funcionários tiveram que eles pegar dinheiro do bolso, comprar o que precisava, material não tem material, não tem material, isso é vergonhoso! Tem equipamento que quebra e fica até dois anos para ser consertado, por quê? Está na decadência, tem quatro cadeiras, só funciona uma, essa uma só funciona porque os dentistas pagam para botar a cadeira para funcionar, sem contar que quando chove dá refluxo no local, refluxo de água de esgoto, muito importante, e sobem assim os ratos, as baratas."

Ideia Central D: A assistência odontológica pública é ruim, por causa dos profissionais

"Nós estamos brigando porque tinham os dentistas que estavam acostumados a não, iam lá um pouquinho, faziam aquele trabalho, faziam de conta que trabalhavam e não trabalhavam. $O$ dentista atende, ele atende cinco pessoas por dia, ele abre o dente, tem uma segunda sessão, ele abre novamente, quando é na terceira, o dente já caiu, então quer dizer, precisa ser encaminhado para outro local. Você vai lá num dia da semana e põe a tal massinha, vai embora para casa, volta na semana que vem, a massinha caiu e tem que limpar de novo com a massinha porque senão vai inflamar se fechar. Não funciona, porque quando você vai num dentista particular, você vai lá e faz dois, três dentes de uma vez em uma hora, e porque no posto de saúde não funciona? Esse tratamento da boca tem que ser não só fazendo a limpezinha e colocar a massinha, mas ter um tratamento odontológico adequado. Existe o próprio cartel entre os dentistas aonde eles não abrem a agenda, se eu tenho que fazer dez consultas, eu faço cinco."

Ideia Central E: A assistência odontológica pública é boa

"Nós temos lá na minha UBS, temos quatro dentistas e eles trabalham muito 
bem, e eu acompanho de perto o trabalho deles."

Os discursos sobre o acesso a serviços odontológicos públicos corroboram achados de estudos anteriores. A assistência odontológica pública é associada à ineficiência e longas filas para se conseguir uma consulta, além da baixa produtividade $^{10}$; apresenta problemas de acesso restrito $^{11}$; gera insatisfação e revolta com o tipo de atendimento que recebem dos serviços oficiais $^{13}$.

As lideranças da UMPS apontam que a assistência odontológica pública é insuficiente para garantir o acesso; não é resolutiva; tem problemas de infraestrutura, como ausência de manutenção e sérias dificuldades organizacionais; dispõe de profissionais que não atendem às exigências da comunidade.

Constata-se que, comparativamente ao quadro geral nacional, a situação do município de São Paulo revela precariedade no acesso ao serviço odontológico público, com reduzida oferta de serviços a adultos e idosos. Indicadores como a Cobertura de Primeira Consulta Odontológica Programática e a Cobertura Populacional Potencial registram valores de menos de $4 \%$ e de cerca de $8 \%$, respectivamente, e caracterizam uma situação de grande distanciamento do princípio constitucional do acesso universal aos cuidados odontológicos.

A emergência do discurso sobre o papel do cirurgião-dentista que atua no serviço público municipal corrobora estudos anteriores. Além do acesso aos cuidados médicos, os usuários reivindicam uma atenção e uma escuta personalizada $^{14}$ e queixam-se do desprezo com que os cirurgiões-dentistas os $\operatorname{tratam}^{10}$. As lideranças da UMPS relataram que os cirurgiõesdentistas da rede pública municipal não cumprem a sua jornada de trabalho; são pouco resolutivos ao prestar cuidados odontológicos e não aceitam controles sobre suas práticas, como a organização do agendamento de usuários.

\section{4a Temática: Conte e explique quando/como surgiu a questão da saúde bucal e o controle social no movimento popular de saúde?}

Ideia Central A: Importância da pressão da população para a organização de serviços assistenciais

"Quando a população pressiona, o serviço melhora. Em saúde bucal é a mesma coisa, onde a população cobra, vai ter o serviço. Porque a saúde bucal como todo na saúde, só quando a população se organiza e cobra que acontece. Do contrário não acontece. É só na luta que a gente consegue as coisas."

Ideia Central B: Importância da informação para a conscientização da população "Então, é informação. É, tem que fazer campanhas da importância da saúde bucal, e que não é nenhuma mentira, é uma verdade. Porque muita gente, por exemplo, junta dinheiro para fazer, pôr silicone nos peitos, mas não junta dinheiro para pôr um implante dentário. Então, é necessário ter uma, talvez seja com campanha, por exemplo, que a gente comece a ter essa consciência para poder cobrar do conselheiro, que a população cobre, o pobre não tem essa consciência. Eu acho que o que está faltando é um pouco de informação com relação a saúde bucal."

Ideia Central C: Inexistência de controle social na saúde bucal 
"Na saúde bucal não existe controle social. Da unidade básica de saúde, mas intenso assim com a saúde bucal não. Porque, e você falar uma coisa sobre a saúde bucal eles falam: não devemos satisfação a vocês! Tem um setor de profissionalismo que não aceita $o$ conselho e nunca sentou com o conselho, que é o dos dentistas. E quando você questiona alguma coisa dos dentistas, eles falam assim: mas a gente não tem nada a ver com vocês. Os dentistas falam, então há essa controvérsia, eles não querem aceitar o controle social. Então fica solto, profissional da saúde bucal está solto, ninguém tem que dar satisfação a ninguém, você não tem que me perguntar nada, cuida da vida de vocês e eu cuido da minha."

Ideia Central D: Há controle social na saúde, não só específico para a saúde bucal

"O controle social, que nós somos conselheiros, ele centra qualquer área dentro da saúde, se eu sou um gestor de uma unidade, seja na questão odontológica, seja em outras questões, o controle social é para tudo que tiver ali em qualquer área, específico."

Ideia Central E: Transparência na construção e definição das políticas

"Se os conselhos locais e o próprio conselho municipal, ele tomar uma atitude de fazer com que essas parceiras prestassem conta, exclusivamente da questão da saúde bucal, por exemplo, quantos profissionais você tem, quantos médicos, quantos dentistas você tem ali, você exigir-se de como é que está o quadro, como é que está funcionando o programa da saúde bucal em cada uma dessas parceiras. Mesmo na UBS, a gente nunca discutiu sobre saúde bucal. E é uma nova discussão que a gente precisa discutir."

Observa-se em São Paulo, que há o entendimento de que a organização da população é condição necessária para a organização de serviços assistenciais, por parte do Estado. Há um forte componente do conceito de saúde enquanto direito de cidadania, e de que a luta política e social é um vetor para a organização de redes assistenciais. A organização e a luta da população, na busca do reconhecimento da cidadania, foram fatores associados ao acesso a serviços públicos coletivos, como saúde, educação e urbanização.

A informação sobre saúde bucal foi destacada como elemento central para a conscientização da sociedade sobre a importância da saúde bucal. Houve sugestão de realização de campanhas neste sentido, por parte de lideranças do movimento popular de saúde.

A produção científica sobre os debates do tema saúde bucal nas Conferências e nos Conselhos de Saúde é exígua. Em relação à especificidade da saúde bucal no controle social, emergiram falas contraditórias. O controle social seria necessário e aplicado em toda a política de saúde, não só na saúde bucal. A necessidade de se garantir a transparência na construção e definição das políticas emergiu com muita força. Tal achado pode ser associado aos vários relatos envolvendo os problemas da gestão no município de São Paulo, que emergiram com grande vitalidade nos grupos. Vários discursos apontaram a contradição entre as iniciativas adotadas pelo governo federal, na implantação do Brasil Sorridente, e a situação de paralisia existente no município paulistano. 
A ausência de controle social na saúde bucal também foi creditada à prática profissional dos cirurgiões-dentistas. A pouca participação de cirurgiões-dentistas, técnicos e auxiliares em saúde bucal nos conselhos gestores locais em unidades de saúde foi apontada em estudo anterior ${ }^{17} \mathrm{e}$ o controle social fora o princípio organizativo do SUS menos lembrado por cirurgiões-dentistas da rede pública ${ }^{18}$.

\section{CONCLUSÕES}

As representações sociais de saúde bucal das lideranças da UMPS indicam um conjunto de vivências, valores, significados, noções, aspirações, desejos e interesses, próprios de lideranças desses segmentos e estratos sociais. Expressam também, com clareza, sua visão de mundo e das relações sociais, bem como sua inserção social, destacando-se a condição subalterna com que conseguem influenciar, em algum grau, o processo de decisões sobre as políticas públicas de interesse para a saúde.

As lideranças da UMPS reconhecem que saúde e doença constituem um processo socialmente determinado e que a organização da população é condição necessária para a implantação e manutenção de serviços assistenciais, por parte do Estado. Há um forte componente do conceito de saúde enquanto direito de cidadania, sendo compreendida também a noção de que a luta política e social é um vetor para a organização de redes assistenciais que possibilitem o exercício desse direito.

O estudo apresenta limitações, pelo fato de ter sido conduzido em um único município e pela escassez de análises desse assunto. Cabe realçar que, dadas suas características socioeconômicas e políticas, o que ocorre em São Paulo possa também ser reproduzido em outras localidades.

\section{ABSTRACT \\ Conceptions of health leaderships on oral health and control of public policies}

We analyze the social representations about oral health and social control among leaders in the Health Area in São Paulo. The research was qualitative, with analytical-descriptive orientation, using the methodological procedure of the Discourse of the Collective Subject. The healthdisease process was recognized as socially determined. The failure to identify oral health as a priority was attributed to the lack of concern of the population, economic factors, and governments. Leadership points out that public dental care is insufficient to guarantee access; it is not resolutive; has infrastructure problems; and has professionals who do not meet the demands of the community.

Descriptors: Public Health Policy. Health Services Accessibility. Community Participation. Dental Health Services.

\section{REFERÊNCIAS}

1. Brasil. Lei Federal $\mathrm{n}^{\circ} 8.142 / 90$, de 28/12/1990. Diário Oficial da União. $31 \mathrm{dez}$ 1990. Seção 1: p. 25.694.

2. Manfredini MA. Saúde bucal coletiva e cidadania: construção social do campo das práticas e da produção dos sentidos. In: Lopes MGM (org). Saúde bucal coletiva: implementando ideias, concebendo integralidade. Rio de Janeiro: Rubio; 2008.

3. Narvai PC, Frazão P. Saúde bucal no Brasil: muito além do céu da boca. Rio de Janeiro: Ed. Fiocruz; 2008.

4. Bógus CM, Martins CL, Dimitrov P, Fortes PAC, Capucci PF, Nemes Filho A, et al. Programa de capacitação permanente de conselheiros populares de saúde na cidade de São Paulo. Saúde Soc. 2003;12(2):56-67. 
5. Neder CAP. Participação e gestão pública: a experiência dos movimentos populares de saúde no município de São Paulo [dissertação]. Campinas: Faculdade de Ciências Médias da Universidade Estadual de Campinas; 2001.

6. Lefèvre F, Lefèvre AMC. Discurso do sujeito coletivo: um novo enfoque em pesquisa qualitativa (desdobramentos). Caxias do Sul: EDUCS; 2003.

7. Abreu MHNG, Pordeus IA, Modena CM. Representações sociais de saúde bucal entre mães no meio rural de Itaúna (MG), 2002. Ciênc Saúde Coletiva. 2005;10(1):245-59.

8. Ferreira AAA. Representações sociais da necessidade de cuidados bucais: um estudo com habitantes do Bairro de Cidade da Esperança [dissertação]. Natal: Centro de Ciências da Saúde da Universidade Federal do Rio Grande do Norte; 2002.

9. Martins EM. Construindo o valor saúde bucal. Ação Coletiva. 1999;2(2):5-9.

10. Santos LE. O discurso popular em Odontologia. Belo Horizonte: DOPUCMG; 1981.

11. Ferreira AAA, Alves MSCF. Os sentidos da boca: um estudo de representações sociais com usuários dos serviços de saúde. Cad Saúde Colet. 2006;14(1):19-30.

12. Mendonça TC. Mutilação dentária: concepções de trabalhadores rurais sobre a responsabilidade pela perda dentária. Cad Saúde Pública. 2001;17(6):1545-47.

13. Braga OFC, Elias L, Mendonça LL. Dominação e saúde: o saber popular em saúde oral. Belo Horizonte: Arte Livre; 1983.

14. Paixão HH. Saúde e doença: um estudo de representação social. Arq Centro Estud Curso Odontol. 1986;23(1/2):9-17.

15. Cruz JS, Cota LOM, Paixão HH, Pordeus IA.
A imagem do cirurgião-dentista: um estudo de representação social. Rev Odontol. Univ. São Paulo. 1997;11(4):307-13.

16. Hiramatsu DA, Tomita NE, Franco LJ. Perda dentária e a imagem do cirurgião-dentista entre um grupo de idosos. Ciênc Saúde Coletiva. 2007;12(4):1051-56. Manfredini MA. Saúde Bucal no Programa Saúde da Família no Brasil. In: Dias AA (org). Saúde bucal coletiva: metodologia de trabalho e práticas. São Paulo: Ed. Santos; 2006.

17. Villalba JP. Perfil profissional dos cirurgiõesdentistas e o Sistema Único de Saúde: uma reflexão sobre a capacitação para a prática na atenção básica. 2007 [tese]. Campinas: Faculdade de Ciências Médicas da Universidade Estadual de Campinas; 2007.

\section{Correspondência para}

Marco Antonio Manfredini

e-mail: manfra@uol.com.br

Av. Dr. Arnaldo, 715

01246-904, São Paulo/SP 